\title{
Desempenho de Novilhos Santa Gertrudis Confinados Submetidos a Dietas com Diferentes Fontes Protéicas e Silagem de Milho, com ou sem Inoculante ${ }^{1}$
}

\author{
Alfredo Acosta Backes², Luis Maria Bonnecarrère Sanchez ${ }^{3}$, Maria Beatriz Fernandes Gonçalves ${ }^{4}$
}

\begin{abstract}
RESUMO - O presente trabalho foi conduzido com o objetivo de avaliar o efeito de uma dieta alimentar contendo fontes protéicas de diferentes degradabilidades ruminais e silagem de milho preparada com ou sem inoculante PIONEER 1174, no desempenho animal. Foi conduzido um experimento fatorial, em que as fontes protéicas (farinha de carne e osso, uréia e uma mistura de ambas [50:50]) foram combinadas com dois tipos de silagens, formando os seis tratamentos experimentais. Foram utilizados 36 novilhos Santa Gertrudis, com 3,5 anos de idade, distribuídos ao acaso nos tratamentos. Diferenças significativas não foram encontradas entre tratamentos para consumo de matéria seca e as interações entre fontes protéicas ou tipos de silagens também não foram significativas. Para o ganho médio diário de peso não houve diferença significativa entre tratamentos, mas a interação entre fontes protéicas mostrou-se significativa. Os animais alimentados com dietas contendo farinha de carne e ossos apresentaram ganhos significativos em relação aos alimentados com uréia. Contrastes entre tipos de silagens não mostraram diferença.
\end{abstract}

Palavras-chave : confinamento, farinha de carne, inoculante, silagem, uréia

\section{Animal Performance of Feedlot Santa Gertrudis Steers Fed Diets with Different Protein Sources and Corn Silage, with or without Inoculant}

\begin{abstract}
The present work was carried out to evaluate the effect of diets with different protein sources of ruminal degradability and corn silage prepared with or without the inoculant PIONEER 1174 on animal performance. A factorial experiment was conducted, where the protein sources (meat and bone meal, urea and a mixture of both [50:50]) were combined with two types of silage, composing six treatments. Thirty six 3.5 years old Santa Gertrudis steers were randomly assigned to the treatments. There were no difference between treatments for dry matter intake, not even when the interactions were made among protein sources or types of silage. For average daily gain there were no significant differences among treatments, but the interactions among protein sources were significant. Animals fed diets with meat and bone meal showed higher weight gain than those fed urea. Contrasts between types of silage did not show any difference.
\end{abstract}

Key Words: feedlot, inoculant, meat meal, silage, urea

\section{Introdução}

Os animais jovens possuem exigência protéica elevada, por estarem em crescimento e, conseqüentemente, em fase de formação muscular, na qual a proteína atua como o principal constituinte deste tecido.

As proteínas podem apresentar alta, média ou baixa degradabilidade no rúmen. Muitas proteínas fornecidas aos ruminantes são degradadas rapidamente pelos microorganismos do rúmen, enquanto outras, particularmente aquelas de origem animal, são resistentes à degradação ruminal (ORSKOV, 1997).

Os microorganismos ruminais produzem a proteína bacteriana, considerada de médio valor biológico, pela utilização do nitrogênio derivado dos alimentos. O nitrogênio do alimento, conforme ORSKOV (1997), está dividido entre o que é degradado no rúmen, tornando-se incorporado na proteína microbiana ou perdido como amônia, e o que não é degradado no rúmen, podendo ser digerido no intestino delgado.

Existe uma quantidade mínima de nitrogênio que deve ser colocado à disposição dos microorganismos ruminais. Conforme o NATIONAL RESEARCH COUNCIL - NRC (1984), a oferta de amônia pode ser inadequada, quando o consumo de proteína ou a degradação ruminal desta proteína é baixa. Portanto, torna-se extremamente necessária a utilização de uma fonte de nitrogênio de boa degradabilidade ou, no

\footnotetext{
${ }^{1}$ Parte da dissertação apresentada pelo primeiro autor para obtenção do grau de Mestre em Zootecnia na Universidade Federal de Santa Maria (UFSM).

2 Zootecnista, MSc, estudante de doutorado da UFV - Av. JK, nº 200, Santa Clara-Viçosa-MG, Cep: 36570-000. E.mail:abackes@bol.com.br 3 Engenheiro-agrônomo, PhD, Professor titular do Departamento de Zootecnia da Universidade Federal de Santa Maria.

4 Zootecnista, MSc, Professora adjunta do Departamento de Zootecnia da Universidade Federal de Santa Maria.
} 
caso de oferta de proteína de alta digestibilidade intestinal, de uma fonte de nitrogênio de alta degradabilidade ruminal, como forma de suprir as exigências microbianas.

Segundo PASCOAL (1992), a disponibilidade de nitrogênio degradável no rúmen, se não for suficiente, limitará a fermentação ruminal, diminuindo o consumo e a eficiência energética do alimento. Isto acontece pelo fato de $75 \%$ dos carboidratos digeridos pelos ruminantes serem fermentados pelos microorganismos do rúmen (NRC, 1984). Uma forma de suprir as exigências microbianas e aumentar a taxa de síntese de proteína bacteriana seria a utilização de uma fonte de nitrogênio de alta degradabilidade, como a uréia, que é totalmente degradável no rúmen até a forma de amônia, ficando disponível para ser utilizada pela população bacteriana.

Atualmente, as normas de alimentação, como as do NRC (1996), possuem como objetivo principal melhorar o manejo dos nutrientes por meio de uma alimentação animal mais aperfeiçoada, por avaliações de nutrientes passantes, como proteínas de alto valor biológico, e por intermédio de estudos sobre a degradação ruminal.

Um dos volumosos mais utilizados em sistemas de animais confinados é a silagem de milho, pelo seu valor nutritivo. Em muitos lugares do Brasil, como no interior do Rio Grande do Sul e em Santa Catarina, é retirada boa parte das espigas de milho verde para serem comercializados em feiras. A planta que sobra na lavoura, com poucas espigas, é geralmente utilizada na alimentação animal na forma de silagem, resultando em silagem de baixa qualidade, devido, principalmente, ao seu baixo valor energético.

A população bacteriana da silagem pode ser aumentada por meio da adição de inoculantes à base de bactérias lácticas e homofermentativas, objetivando formação de ácido láctico. Conforme VAN SOEST (1994), os aditivos têm duas principais vantagens na silagem: influenciar a fermentação, favorecendo a preservação, e alterar a composição, melhorando o valor nutritivo.

Objetivando avaliar a composição bromatológica da silagem de milho, SILVA (1997) utilizou um tipo de inoculante bacteriano (PIONNER 1174) na silagem, sendo aplicado no processo de compactação na dosagem de $50 \mathrm{~g}$ do produto para $90 \mathrm{~L}$ de água e pulverizando $2 \mathrm{~L}$ de solução por tonelada de forragem. Concluiu que o inoculante bacteriano não alterou a composição bromatológica em termos de MS,
MO, FDA, NDT e DIVMO, mas produziu silagens com maior teor de $\mathrm{PB}(6,09$ e 5,77\%, respectivamente, com e sem inoculante) e menos FDN (59,56 e $61,83 \%$, respectivamente, com e sem inoculante).

O objetivo do presente trabalho foi avaliar a utilização de fontes protéicas de diferentes degradabilidades associadas à silagem de milho, com e sem inoculante PIONNER 1174, no desempenho de novilhos confinados.

\section{Material e Métodos}

Foram utilizados 36 animais da raça Santa Gertrudis, machos castrados, com idade média de 3,5 anos e peso médio inicial de $390 \mathrm{~kg}$. Estes animais foram confinados em instalações pertencentes ao Setor de Nutrição Animal do Departamento de Zootecnia da Universidade Federal de Santa Maria, por um período de 105 dias, divididos em cinco subperíodos de 21 dias, sendo que a pesagem dos animais foi realizada após jejum de 16 horas, no início do experimento e no final de cada subperíodo.

Os tratamentos foram compostos por um fatorial $3 \times 2$, ou seja, duas fontes protéicas (farinha de carne e osso e uréia) e uma mistura proporcional destas (50:50), e dois tipos de silagem (com e sem inoculante 1174 da PIONNER), totalizando seis tratamentos experimentais: farinha de carne e osso + silagem com inoculante; farinha de carne e osso + silagem sem inoculante; uréia + silagem com inoculante; uréia + silagem sem inoculante; farinha de carne e osso + uréia + silagem com inoculante e farinha de carne e osso + uréia + silagem sem inoculante.

A composição bromatológica dos alimentos volumosos e concentrados é mostrada na Tabela 1 .

Os valores médios de matéria seca obtidos neste trabalho, para as silagens de milho com ou sem inoculante, são considerados ideais para o processo de fermentação e assemelham-se ao valor encontrado por MUHLBACH (1998).

Observou-se maior teor de matéria mineral para o concentrado contendo somente farinha de carne e osso como fonte protéica, o que pode ser devido à maior quantidade desta fonte protéica neste concentrado (Tabela 2).

As dietas foram formuladas para serem isoprotéicas, sendo seus componentes apresentados na Tabela 2.

Os animais foram arraçoados à vontade, duas vezes ao dia. A proporção volumoso:concentrado foi

Rev. bras. zootec., 30(6S):2121-2125, 2001 
Tabela 1 - Conteúdo de matéria seca total (MST), matéria orgânica (MO), proteína bruta (PB), fibra bruta (FB), matéria mineral $(\mathrm{MM})$ e extrativo não-nitrogenados (ENN) das silagens e concentrados

Table 1 - Contents of total dry matter (TDM), organic matter (OM), crude protein (CP), crude fiber (CF), mineral matter (MM) and nitrogenfree extract (NFE) of the silages and concentrates

\begin{tabular}{|c|c|c|c|c|c|c|}
\hline Alimento & $\operatorname{MST}(\%)+$ & $\mathrm{MO}(\%)^{*}$ & $\mathrm{~PB}(\%)^{*}$ & $\mathrm{FB}(\%)^{*}$ & $\operatorname{MM}(\%)^{*}$ & $\operatorname{ENN}(\%)^{*}$ \\
\hline Feed & $T D M$ & $O M$ & $C P$ & $C F$ & $M M$ & $N F E$ \\
\hline SM/C-INOC & 34,75 & 97,29 & 6,35 & 23,8 & 2,71 & 62,58 \\
\hline SM/S-INOC & 35,14 & 96,76 & 6,53 & 23,8 & 3,24 & 64,29 \\
\hline CONCF.CARNE & 93,55 & 93,28 & 16,18 & 1,91 & 6,72 & 69,71 \\
\hline CONCUR & 98,27 & 98,25 & 16,44 & 2,06 & 1,75 & 76,31 \\
\hline $\mathrm{CONCFC+UR}$ & 95,88 & 95,81 & 16,37 & 1,99 & 4,19 & 73,05 \\
\hline
\end{tabular}

$+=$ matéria natural.

* = matéria seca total.

SM/C-INOC = silagem de milho com inoculante; SM/S-INOC = silagem de milho sem inoculante; CONC F . CARNE = concentrado com farinha e carne e ossos; CONC UR = concentrado com uréia; CONC FC+UR = concentrado com farinha de carne e osso mais uréia.

$+=$ fresh matter.

* $=$ total dry matter

$S M / C-I N O C=$ corn silage with inoculant; SM/S-INOC = corn silage without inoculant; CONCF. CARNE = concentrate with meat and bone meal; CONC UR = concentrate with urea; CONC FC + UR = concentrate with meat and bone meal + urea.

Tabela 2 - Composição da ração fornecida aos animais, em percentagem da matéria seca total (\%MST)

Table 2 - Composition of the diet fed to the animals, in total dry matter percentage (TDM\%)

\begin{tabular}{|c|c|c|c|c|c|c|}
\hline $\begin{array}{l}\text { Ingredientes } \\
\text { Ingredients }\end{array}$ & $\mathrm{T} 1$ & $\mathrm{~T} 2$ & $\mathrm{~T} 3$ & $\mathrm{~T} 4$ & T5 & T6 \\
\hline $\begin{array}{l}\text { Silagem de milho com inoculante } \\
\text { Corn silage with inoculant }\end{array}$ & 70,00 & - & 70,00 & - & 70,00 & - \\
\hline $\begin{array}{l}\text { Silagem de milho sem inoculante } \\
\text { Corn silage without inoculant }\end{array}$ & - & 70,00 & - & 70,00 & - & 70,00 \\
\hline $\begin{array}{l}\text { Milho } \\
\text { Corn }\end{array}$ & 22,63 & 22,63 & 28,55 & 28,55 & 25,83 & 25,83 \\
\hline $\begin{array}{l}\text { Farinha de carne e ossos } \\
\text { Meat and bone meal }\end{array}$ & 7,20 & 7,20 & - & - & 3,36 & 3,36 \\
\hline $\begin{array}{l}\text { Uréia } \\
\text { Urea }\end{array}$ & - & - & 0,93 & 0,93 & 0,50 & 0,50 \\
\hline $\begin{array}{l}\mathrm{Sal}(\mathrm{NaCl}) \\
\text { Salt }\end{array}$ & 0,10 & 0,10 & 0,12 & 0,12 & 0,12 & 0,12 \\
\hline $\begin{array}{l}\text { Farinha de osso calcinado } \\
\text { Roasted bone flour }\end{array}$ & 0,07 & 0,07 & 0,18 & 0,18 & 0,06 & 0,06 \\
\hline $\begin{array}{l}\text { Sulfato de amônia } \\
\text { Ammonia sulfate }\end{array}$ & - & - & 0,22 & 0,22 & 0,13 & 0,13 \\
\hline
\end{tabular}

$\mathrm{T} 1$ = farinha de carne e ossos + silagem com inoculante; $\mathrm{T} 2$ = farinha de carne e ossos + silagem sem inoculante; $\mathrm{T} 3=$ uréia + silagem com inoculante; $\mathrm{T} 4=$ uréia + silagem sem inoculante; $\mathrm{T} 5$ = farinha de carne e ossos + uréia + silagem com inoculante; $\mathrm{T} 6=$ farinha de carne e ossos + uréia + silagem sem inoculante.

$T 1=$ meat and bone meal + silage with inoculant; $T 2=$ meat and bone meal + silage without inoculant; $T 3=$ urea + silage with inoculant; $T 4=$ urea + silage without inoculant; $T 5=$ meat and bone meal + urea + silage with inoculant; $T 6=$ meat and bone meal + urea + silage without inoculant .

de 70:30, sendo o concentrado fornecido misturado à silagem, na hora do arraçoamento.

O delineamento utilizado foi inteiramente casualizado com duas repetições; cada repetição era composta por três animais. Procedeu-se a análises de variância e teste F; quando este se apresentou significativo, foi realizado o teste de Tukey, utilizando-se o Sistema de Análise Estatística - SAS (SAS, 1985).

\section{Resultados e Discussão}

Na Tabela 3 são mostrados os valores de consumo de MS de todos os tratamentos, não tendo havido diferença significativa entre eles. Também são apresentados valores para conversão alimentar (CA) e ganho médio diário (GMD). Verifica-se que, para conversão alimentar, não houve diferença significativa entre os tratamentos. 
Trabalhando com diferentes fontes protéicas (farelo de soja, farelo de soja + uréia e uréia), FEIJÓ (1997) obteve a pior conversão alimentar (7,52) para a dieta contendo uréia como fonte protéica, valor semelhante ao encontrado neste trabalho. Ao trabalhar com diferentes categorias animais, QUADROS (1994) obteve, para a categoria novilhos, valores de conversão alimentar de 6,07 para dietas com farinha de carne e de 6,68 para dietas com uréia, obtendo, assim, pior conversão para a dieta com uréia. As conversões encontradas neste trabalho, para dietas com farinha de carne e ossos e dietas com uréia, foram inferiores às observadas pelo autor acima, como verificado na Tabela 3 .

Não houve diferença no consumo entre tratamentos e na interação entre fontes protéicas e tipos de silagem. Para ganho médio diário, não houve diferença significativa entre os tratamentos, havendo interação significativa apenas entre a fonte protéica uréia e a fonte protéica farinha de carne e osso.

Na Tabela 4 são mostrados os valores obtidos de consumo médio voluntário, em quilograma de MS e por $100 \mathrm{~kg}$ de peso vivo, em função das diferentes fontes protéicas. O consumo voluntário de MS não apresentou diferença significativa, a $5 \%$, entre as dietas com diferentes fontes protéicas.

QUADROS (1994) obteve valores de consumo de MS superiores para dietas com farinha de carne em relação a dietas com uréia.

Com relação ao ganho médio diário mostrado na Tabela 4, observa-se que os tratamentos com farinha de carne e osso diferiram significativamente dos tratamentos contendo apenas uréia como fonte protéica, e esta não diferiu dos tratamentos contendo ambas as fontes.

Trabalhando com terneiros desaleitados precocemente, alimentados com dois tipos de fonte protéica (uréia e farinha de carne), KOZLOSKI (1995) obteve $13 \%$ a mais em ganho médio diário, com o tratamento contendo farinha de carne. A média de ganho de peso dos tratamentos que continham farinha de carne foi significativamente superior àquela contendo uréia em 13,78\% (PASCOAL, 1992). QUADROS (1994) obteve uma vantagem no ganho médio diário a favor da farinha de carne, em relação à uréia, de $15,5 \%$, valores inferiores ao encontrado neste trabalho, $17,5 \%$ a favor da farinha de carne e ossos. Esta vantagem pode ser decorrente do melhor aproveitamento dos aminoácidos desta fonte no intestino delgado, já que é considerada uma proteína passante e de alto valor biológico.

Com relação ao consumo voluntário para os diferentes tipos de silagem, não houve diferença significativa, a $5 \%$, como mostrado na Tabela 5 .

Em termos de consumo em $\mathrm{kg}$ de MS, praticamente não se verificou diferença entre silagens de milho com e sem inoculante. No entanto, segundo MUHLBACH (1998), existem experimentos com vacas em lactação e gado de corte alimentados com silagem inoculadas, que indicam aumento no consumo de MS e melhora no desempenho e na eficiência alimentar, fatos que não foram verificados no presente trabalho.

Tabela 3 - Consumo de matéria seca (CMS) por 100 kg de peso vivo (PV), conversão alimentar (CA) e ganho médio diário (GMD) Table 3 - Dry matter intake (DMI) for $100 \mathrm{~kg}$ of live weight (LW), feed:gain ratio (F/G) and average daily weight gain (DLW)

\begin{tabular}{|c|c|c|c|}
\hline $\begin{array}{l}\text { Tratamentos } \\
\text { Treatments }\end{array}$ & $\begin{array}{l}\text { CMS (kg/100 kg PV) } \\
D M I(k g / 100 \mathrm{~kg} \mathrm{LW})\end{array}$ & $\begin{array}{l}\mathrm{CA}(\mathrm{kg}) \\
A C(\mathrm{~kg})\end{array}$ & $\begin{array}{l}\operatorname{GMD}(\mathrm{kg}) \\
D L W(\mathrm{~kg})\end{array}$ \\
\hline $\begin{array}{l}\text { Farinha de carne e ossos }+ \text { silagem com inoculante } \\
\text { Meat and bone meal }+ \text { silage with inoculant }\end{array}$ & 2,09 & 7,03 & 1,322 \\
\hline $\begin{array}{l}\text { Farinha de carne e ossos }+ \text { silagem sem inoculante } \\
\text { Meat and bone meal }+ \text { silage without inoculant }\end{array}$ & 2,13 & 7,40 & 1,332 \\
\hline $\begin{array}{l}\text { Uréia }+ \text { silagem com inoculante } \\
\text { Urea }+ \text { silage with inoculant }\end{array}$ & 2,02 & 8,28 & 1,032 \\
\hline $\begin{array}{l}\text { Uréia }+ \text { silagem sem inoculante } \\
\text { Urea }+ \text { silage without inoculant }\end{array}$ & 1,99 & 7,32 & 1,154 \\
\hline $\begin{array}{l}\text { Farinha de carne e ossos }+ \text { uréia }+ \text { silagem com inoculante } \\
\text { Meat and bone meal }+ \text { urea }+ \text { silage with inoculant }\end{array}$ & 2,11 & 7,25 & 1,311 \\
\hline $\begin{array}{l}\text { Farinha de carne e ossos }+ \text { uréia }+ \text { silagem sem inoculante } \\
\text { Meat and bone meal }+ \text { urea }+ \text { silage without inoculant }\end{array}$ & 2,16 & 7,34 & 1,243 \\
\hline $\mathrm{CV}$ & 2,24 & 14,35 & 18,14 \\
\hline
\end{tabular}

${ }^{1} \mathrm{CV}=$ Coeficiente de variação (coefficient of variation).

Rev. bras. zootec., 30(6S):2121-2125, 2001 
Tabela 4 - Valores médios de consumo voluntário em porcentagem da matéria seca e por $100 \mathrm{~kg}$ de peso vivo e ganho médio diário (GMD) em kg/animal/dia, para as dietas com diferentes fontes protéicas

Table 4 - Average values of voluntary intake in percentage of the dry matter and for $100 \mathrm{~kg}$ of live weight and average daily weight gain $(D L W)$ observed in $\mathrm{kg} / \mathrm{animal} / \mathrm{day}$, for the diets with different protein sources

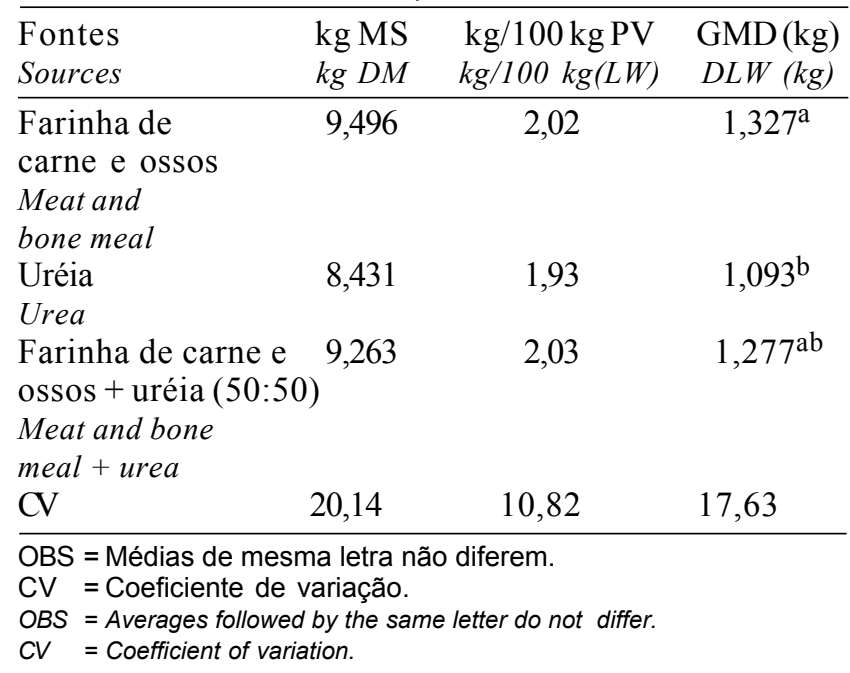

Tabela 5 - Valores médios de consumo voluntário em porcentagem da matéria seca e por $100 \mathrm{~kg}$ de peso vivo e ganho médio diário observado em kg/ animal/dia, para as dietas com diferentes tipos de silagem

Table 5 - Average values of voluntary intake in percentage of the dry matter and for $100 \mathrm{~kg}$ of live weight and average daily live weight gain observed in $\mathrm{kg}$ animal/day, for the diets with different types of silage

\begin{tabular}{lccc}
\hline $\begin{array}{l}\text { Dietas } \\
\text { Diets }\end{array}$ & $\mathrm{kg}$ MS & $\mathrm{kg} / 100 \mathrm{~kg}$ PV & $\mathrm{GMD}(\mathrm{kg})$ \\
$\mathrm{kg} / 100 \mathrm{~kg}(\mathrm{LW})$ & $\mathrm{DLW}(\mathrm{kg})$ \\
$\begin{array}{l}\text { Silagem de milho } \\
\text { com inoculante }\end{array}$ & 9,029 & 1,98 & 1,221 \\
$\begin{array}{l}\text { Corn silage with } \\
\text { inoculant }\end{array}$ & & & \\
$\begin{array}{l}\text { Silagem de milho } \\
\text { sem inoculante } \\
\text { Corn silage without }\end{array}$ & 9,093 & 2,01 & 1,257 \\
inoculant \\
$\mathrm{CV}$
\end{tabular}

Os ganhos médios diários dos tratamentos com diferentes tipos de silagem (com e sem inoculante PIONNER 1174) também são mostrados na Tabela 5, não tendo sido encontrada diferença significativa entre estes dois tipos de silagem.

O fato de as silagens usadas neste experimento serem de boa qualidade pode ter sido o motivo de o inoculante não ter surtido o efeito esperado.

\section{Conclusões}

As dietas formadas pelas fontes protéicas (farinha de carne e ossos, uréia e uma mistura proporcional destas) e pelos tipos de silagem (com e sem inoculante) não influenciaram o consumo de matéria seca e a conversão alimentar de novilhos Santa Gertrudis confinados.

A utilização da farinha de carne e osso proporcionou melhor ganho de peso em relação ao uso exclusivo de uréia como fonte protéica.

$\mathrm{O}$ uso do inoculante formado por Lactobacilus faecium e plantarum (PIONNER 1174) não melhorou, significativamente, o ganho de peso e o consumo de matéria seca.

\section{Referências Bibliográficas}

FEIJÓ, G.L.D. Efeito de fontes de nitrogênio e do tipo de silagem no desempenho de bovinos F1 Pardo Suíço x Nelore. In: REUNIÃO ANUAL DA SOCIEDADE BRASILEIRA DE ZOOTECNIA, 34., 1997, Juiz de Fora. Anais... Juiz de Fora: SBZ, 1997. p.283.

KOZLOSKI, G.V. Alimentação de terneiros com dietas ricas em grãos e suplementados com uréia ou farinha de carne. I. Ganho de peso e consumo de alimentos. In: REUNIÃO ANUAL DA SOCIEDADE BRASILEIRA DE ZOOTECNIA, 32., 1995, Brasília. Anais... Brasília: SBZ, 1995. p.201.

MULBACH, P.1998. Utilização de inoculantes nas silagens. Os aditivos biológicos-enzimas e bactérias-ganham espaço na preparação de silagem, apresentando resultados positivos (I.M):Curitiba-PR. (Boletim Técnico, n.3).

NATIONAL RESEARCH COUNCIL - NRC.1984. Necessidades nutritivas del ganado vacuno. 3.ed. Buenos Aires, Hemisfério Sur. $104 p$.

NATIONAL RESEARCH COUNCIL-NRC.1996. Nutrient requirements of beef cattle. 7.ed. National Academy Press. 243p.

ORSKOV, E.R. Protein and energy evaluation in ruminant with emphasis na total resource managment. In: SIMPÓSIO INTERNACIONAL SOBRE DIGESTIBILIDADE EM RUMINANTES, 1997, Lavras. Anais... Lavras, 1997. p.115.

PASCOAL, L.L.Efeito da proteina de alta ou de baixa degradabilidade ruminal associada a cana de açúcar ou ao capim napier na alimentação de bovinos confinados. Santa Maria, RS: UFSM, 1992. 185p. Dissertação (Mestrado em Zootecnia) Universidade Federal de Santa Maria, 1992.

QUADROS, A.R.B. Avaliação de duas fontes de proteína na alimentação de bovinos de diferentes idades, em regime de confinamento. Santa Maria, RS: UFSM, 1994. 163p. Dissertação (Mestrado em Zootecnia) - Universidade Federal de Santa Maria, 1994.

SACCOL, A.G.F. Valor nutritivo do resíduo da pré-limpeza do arroz. Santa Maria, RS: UFSM, 1994. 121p. Dissertação (Mestrado em Zootecnia) - Universidade Federal de Santa Maria, 1994.

SILVA, A.W.L. Efeito do uso de inoculantes bacterianos e de diferentes proporções de grãos na massa sobre a composição bromatológica da silagem de milho. In: REUNIÃO ANUAL DA SOCIEDADE BRASILEIRA DE ZOOTECNIA, 34., 1997, Juiz de Fora. Anais...Juiz de Fora: SBZ, 1997, p.170.

SISTEMA DE ANÁLISE ESTATÍSTICA-SAS. 1985. Pacote estatístico.

VAN SOEST, P.J. 1994. Nutritional ecology of the ruminant. 2.ed. Ithaca: Cornell. 476p.

Recebido em: $16 / 11 / 00$

Aceito em: 17/08/01

Rev. bras. zootec., 30(6S):2121-2125, 2001 